\title{
DIE EPIFANIE IN DIE OU TESTAMENT EN SY KONSEKWENSIES VIR DIE TEOLOGIE
}

\author{
PROF. DR. J. P. OBERHOLZER
}

Die teologiese student ontdek telkens tot sy verbystering dat daar oor min teologiese sake eenstemmigheid bestaan. Dit geld nie net die interpretasie van die inhoudelike materiaal van die teologie nie, maar ook die terminologie. Om die probleem meteens te verskerp, kan ons sê dat met epifanie hier bedoel word die teofanie met die oog op die Godsdaad in die geskiedenis. Afgaande op die Griekse oorsprong, beteken "teofanie” "Godsverskyning”, en „epifanie” net „verskyning”. Elkeen van die woorde het egter 'n geskiedenis. In die vroeë Christelike kerk is „teofanie" byna uitsluitlik gebruik vir die openbaring van God en van sy heerlikheid in Christus. Die fees waarop die geboorte van Christus gevier is, is Teofaniefees genoem, met ander woorde die fees wat die verskyning van God in Christus, die vleeswording, gevier het. Mettertyd het daarnaas die term „epifanie" gekom as aanduiding van die selfgetuienis van God by die dood van Christus. Die Epifaniefees wat vandag nog in sommige kerke op 6 Januarie gevier word, het gewoonlik die aanwysing van Jesus as Messias of as Seun van God tot onderwerp. In die Bybels-teologiese spraakgebruik is later die term "teofanie" aangewend vir dié openbaringsvorms waarin die persoon van God op een of ander wyse in ruimtelike sin met die mens in verhouding tree. ${ }^{1}$ ) Kenmerkend van hierdie verskyning is dat dit van verbygaande aard is. Die teenwoordigheid van God in die tabernakel of tempel in die vorm van sy heerlikheid of naam, sal dus nie as teofanie beskou word nie, ook nie openbaringsvorme soos drome en visioene waar God op een of ander wyse op sy hemelse troon waargeneem word nie.

Op hierdie wyse beperk, omvat die teofanie dan daardie verskynings van God waarvan die beskrywing normaalweg uit twee komponente plus ' $n$ derde bestaan. ${ }^{2}$ ) Die eerste komponent is die vermelding van die koms van God deur middel van werkwoorde van beweging soos „kom, stap, tree, afkom” ens. Die tweede komponent is die beskrywing van die kosmiese beroeringe wat hierdie koms van God begelei: vuur, wind en storm, stortreën en hael, donder, aardbewings, opdroog van die waters, verwelking van die plantegroei, ens. Die derde komponent is die handeling van God wat op sy koms volg. Hierdie derde komponent is gewoonlik nie deel van die teofaniebeskrywing self 
nie, maar moet uit die konteks afgelei word. So kan ons uit die konteks van die teofaniebeskrywing in Ex. 19 en 20 aflei dat die Here na Sinai kom met die doel om met Moses en die volk te praat. Hy het gekom om sy wil aan die volk wat Hy uit Egipte verlos het. bekend te maak in die vorm van die Tien Gebooie. Dergelike teofanieë wat op wilskommunikasie uitloop, het ons in die roeping van Moses by die brandende bos (Ex. 3) en in die korreksie en terugsending van Elia by Horeb (1 Kon. 19). Daar is egter ' $n$ ander reeks teofaniebeskrywings waar die derde komponent nie 'n woordopenbaring is nie, maar 'n handelende in. gryping van God in die geskiedenis. So word byvoorbeeld in die lofsang van Debora, Rigt. 5, die koms van die Here beskryf as die grond van die oorwinning van Barak oor die Kanaäniete. Dit was 'n oorlog wat deur die Here self geveg is (vgl. vs. 13, 23). Van dergelike teofanieë wat op 'n handelende ingryping van God ten behoewe van sy uitverkorenes uitloop, is daar in die $\mathrm{Ou}$ Testament 'n hele reeks, en dit is hierdie reeks wat die onderwerp van hierdie oorsig vorm. Westermann het in sy behandeling van dieselfde reeks 'n terminologiese onderskeiding ingevoer, naamlik teofanie vir die Godsverskynings wat openbaring ten doel het en epifanie vir die verskynings wat uitloop op hulp aan die Godsvolk. Hy maak hierdie onderskeiding om bloot praktiese redes, maar oorkom daarmee nie die probleem van die semantiese wisselbaarheid van die twee terme en van die historiese beladenheid van die begrippe nie. Ten spyte daarvan het sy onderskeiding navolging gevind, $e_{i n}$ dit is 'n ooreenstemming met die heersende gebruik dat ons hier ook die term epifanie gebruik vir die reeks teofanieë. ${ }^{3}$ )

Dat dit noodsaaklik is om die twee kategorieë te onderskei, word duidelik as ons vra na die plek wat elkeen inneem in die teologie van die Ou Testament, en ook na die herkoms van die epifaniebeskrywirg as vaste stylvorm. Westermann het daarop gewys dat nie net die doel van die Godsverskyning nie maar ook die gebeurtenis van die Godsverskyning self in die twee kategorieë verskillend is. Wanneer hy die teofanie van Ex. 19 en die epifanie in Rigt. 5 met mekaar vergelyk, vind hy die volgende onderskeide: (a) In Ex. 19 word die afdaal van God op 'n berg berig; in Rigt. 5 word die koms van God van 'n bepaalde plek af berig. (b) In Ex. 19 is die by die naam genoemde, vaste plek die bestemming van die koms van God; in Rigt. 5 is die by die naam genoemde, vaste plek die vertrekpunt van die koms van God. (c) Die plek van verskying in Ex. 19 is deur God self bepaal; in Rigt. 5 is die plek van verskyning die toneel van die nood van sy volk. 
Ook ten opsigte van die begeleidende verskynsels vind Westermann meer verskille as ooreenkomste. Hy toon aan dat waar daar in Ex. 19 sprake is van die bewe van die berg, in die reeks wat uitloop op Gods hulp aan sy volk steeds sprake is van 'n meervoud. Die rook wat in die verskyming by Sinai so 'n belangrike rol speel, kom in die ander reeks net in Ps. 18 voor en dan in ander verband. Die aardbewing ontbreek in die Sinai-reek, terwyl dit in die epifanieë die belangrikste element vorm.

Voordat ons na die herkoms en teologiese plek van die epifaniebeskrywing wat nie woordopenbaring nie maar handeling as derde komponent bevat, kan vra, moet ons eers kortliks kyk na die formele elemente van die epifanieë. Die eerste komponent is die koms van God, wat beskrywe word met 'n verskeidenheid van werkwoorde, hoofsaaklik werkwoorde van beweging. Hierdie werkwoorde, gee reeds iets te kenne van die voorstellings wat daaragter lê. Wanneer daar gesê word dat Jahwe „neergedaal” het (jrd), lê daar agter die gedagte van sy verblyf in sy hemelse woning, van waaruit Hy verskyn en in die geskiedenis optree. In drie gevalle word as vertrekpunt van die epifanie dan ook inderdaad die heriel genoem (Ps. $18^{9} 144^{5}$ Jes. $63^{19}$ ). Wanneer daar gesê word dat Jahwe "uitgetrek" het (js'), herken ons daarin 'n moontlike militêre term, en inderdaad vind ons dat die krygsmotief grondliggend is aan al hierdie epifanieë. Die werkwoorde stap en betree $\left(s^{\prime} \mathrm{d}\right.$, drk, hlk, 'md) bevestig dat die voorstelling van Jahwe as voetgangerkrygsman 'n rol speel. Daarnaas staan dan egter weer die uitdrukkings vir die gebruik maak van 'n voertuig: Jahwe ry op 'n gerub (Ps. 18 ${ }^{11}$ ), met perde op strydwaens $\left(\right.$ Hab. $3^{3}$ ), op die hemele en die wolke (Deut. $33^{23}$ Jes. $19^{1}$ Ps. 68 ${ }^{5.31}$ ) Hier het ons die voorstelling van die Hemelkoning wat op sy strydwa triomferend uittrek vir die stryd. Dat ons hier cok te doen het met mitologiese motiewe, blyk uit die epitheton rkb 'rpt „Wolkeryer” vir Alijan Baäl in die Ugaritiese tekste, wat in Ps. $68^{5}$ van Jahwe gebruik word rkb b'rbwt. ${ }^{4}$ ) So leer ons reeds uit die werkwoorde, net soos in die verwante substantiewe ,pad, paaie, spoor" (Nah. $1^{3}$ Hab. $3^{6}$ Ps. $77^{20}$ ), iets ken van die voorstellings wat met die epifanie in verband staan. Ook die werkwoorde vir "stralend verskyn" (zrh, jp“Hif. Deut. $33^{2}$ ) wat parallel aan werkwoorde vir beweging gebruik word, maak ' $n$ bydrae tot die beeld wat ons van die epifanie kry, en wel in die opsig dat die antropomorfisme van die beweeg werkwoorde getemper word. Die verskyning van Jahwe word daardeur vergelyk met die verskyning van die son, en dui op die ligglans wat 'n begeleidende verskynsel van die epifanie vorm.

Die eerste komponent van die teofaniebeskrywing noem in 10 gevalle ook nog die vertrekpunt van God. In drie gevalle is 
dit die hemel, in een geval word dit aangegee as "uit sy plek" (mimmekômô Mig. $1^{3}$ ) en in een geval as ,van ver af" (Jes. 30 ${ }^{2 i}$ ). In die oorblywende 5 gevalle is die vertrekpunt 'n geografiese lokaliteit. So lees ons in Deut. 33":

Jahwe het van Sinai af gekom en uit Seïr vir hulle uitgestraal

Hy het in ligglans verskyn van die berg Paran af en gekom van heilige tienduisende af.

Rigt. 5': Jahwe, toe U uit Seir uitgetrek het, toe $U$ uit die velde van Edom gestap het . .

Jes. $63^{1} \mathrm{Wie}$ is dit wat van Edom af kom, met bloedrooi klere van Bosra af . .

Hab. $3^{2}$ God sal van Teman af kom en die Heiiige van die berg Paran af

Sag. $9^{14}$ Jahwe sal aan hulle verskyn... en in die siorms van Teman loop

Hiervan kan Edom en Bosra in Jes. $63^{1}$ verval, omdat dit hier juis die plek van Jahwe se optrede aandui. Dit laat ons dus met Sinai, Seir, Paran, die velde van Edom en Teman. Teman is aanduiding van 'n Edomitiese landstreek sowel as van 'n rigting, die Suide $e n$ dit is nie altyd maklik om te beslut watter een bedoel word nie. Die parallel met Paran in Hab. $3^{3}$ beslis gewoonlik daar ten gunste van die pleknaam, maar in Sag. $9^{14}$ word deurgaans vertaal met "storms van die suide".

Sinai is die heilige berg wat in die Pentateug die toneel is van die verskynings van Jahwe wat grondliggend is vir die geheel van die Israelitiese godsdiens. In Deut. word die naam Horeb vir dié berg gebruik. Die mees waarskynlike ligging van die berg is nog steeds die deur die tradisie aangewysde suidelike deel van ciie Sinaiskiereiland.

Seîr is die beı gland oos van die Araba waar aanvanklik die Horiete gewoon het. Die land is later in besit geneem deur die E.domiete, ' $n$ feit wat in Deut. $2^{22}$ Jos. $24^{4}$ aan die direkte ingryping van Jahwe toegeskryf word. In die ou oorlewering oor die woestyntog het Seîr vermelding gevind slegs in die Bileamspreuke waar dit as woonplek van die Edomiete geld. Die Deuteronomium ken die bergland van Seīr ook nie anders nie.

Paran is die woestyngebied wes van die Edomitiese gebied waarin Kades-Barnea geleë was en waarvandaan die eerste verkenning van die beloofde land plaasgevind het (Num. $10^{12}$ $12^{16} 13^{3: 26}$ )

Teman speel in die woestyntog geen rol nie. Dit was die naam van 'n Edornitiese geslag (Gen. 36 $6^{11}:{ }^{15: 42}$ ) en blykbaar van die woonplek van die geslag (Jer. $49^{7}$ Eseg. $25^{13}$ Am. I ${ }^{12}$ Ob. 9), 'n streek in Edom. 
Die skaarse gegewens oor die plekke wat as vertrekpunt van die teofanie aangegee word, is dus van weinig hulp vir 'n insae in die problematiek wat deur die noem van die plekke aan die orde gestel word. Uit die paar plekke waar die hemel en die woonplek van God as vertrekpunt genoem word, is dit logies om af te lei dat ook sinaī, Seĩr, Paran en Teman as woonplekke van God moet geld. Nou wil dit egter uit die parallelle gebruik van hierdie plekname voorkom of hier slegs van een plek sprake is, naamlik Sinai. In Deut. $33^{2}$ is Sinaĩ, Seir en die berg Paran parallel en dui die name skynbaar op een rigting. In Hab. $3^{3}$ is Teman en die berg Paran weer parallel. Die posisie vanwaaruit hierdie teofanieë beskryf word, is steeds die Heilige Land self. Jahwe kom van Sanai af en sy roete word rofweg aangedui as via die Paran en Seïrberge. Soos die volgende aanhaling uit 'n kommentaar van 1824 liat blyk, is hierdie uitsprake van ouds af so verstaan: „Tereg het R. Saadia Haggaon by Aben-Esra hierdie teks verstaan in verband met die staanplek van die Israeliete by die berg Sinai en in verband met die glorieryke koms van Jahwe na die berg en wel só dat daardie geweldige storm, waar-

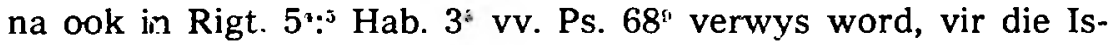
raeliete eerstens in die rigting van Seïr verskyn het, en vollediger van die berg Paran af uitgestraal het, steeds totdat dit uiteindelik op die berg Sinai bly, waarvandaan Hy verder sy volk tegemoet gaan."

Tereg het Mariin Noth egter die aandag daarop gevestig dat in Rigt. 5 die formulering sodanig is dat die uitgangspunt van die koms van Jahwe eerder Seïr self is. O.g.v. Deut. 33 en Rigt. 5 meen hy dat die lokalisering van Sinai in die land Seir steeds 'n mcontlikheid is. ${ }^{6}$ ) Hoe die saak ookal geinterpreteer word, die onsekere omvang van die georgrafiese gebied wat deur Edom, Seîr, Teman aangedui word, en die onsekere lokalisering van die Sinai- en Paranberge, staan hier in die weg van 'n bevredigende interpretasie. Omdat ons nou eenmaal 'n keuse móét maak, aanvaar ons as werkhipotese die tradisionele opvatting dat die vertrekpunt van die epifanieë in elke geval Sinaï is.

Dit bring die vraag na vore wat die verhouding tussen Sinai en die hemel is. Ook hier bring Deut. 33' 'n heel besondere visie na vore. Die vertrekpunt van die teofanie is naamlik Sinaî//Seïr// die berg Paran//heilige tienduisende. Indien die teks ongeskonde is en ons inderdaad "heilige tienduisende" moet lees (Dillman het meribat qadēs voorgestel, vgl. Deut. $32^{\text {s1 }}$ ), dan het ons hier 'n element wat aantoon dat die geografiese denke hier minstens 'n kosmiese geladenheid het. Die ,heilige tienduisende" verwys na die hemelse leërskare wat die troon van die Hemelkoning omring. 'n Ouer geslag van geleerdes het maklik van Sinai gepraat 
as die Godsberg waar Jahwe aanvanklik as 'n lokale godheid sy woning gehad het. Hy sou dan mettertyd van Sinaĩ af verhuis het na die land Kanaän (veral die berg Sion) en eers in die tyd van Esegiël sou hy die aspek van 'n hemelgod aangeneem het. Die opvatting is grondig verwerp deur Eichrodt, wat daarop wys dat dit in uitsprake oor die woonplek van Jahwe nie gaan om 'n sinnelik beperkte, lyflike teєnwoordigheid nie, maar om 'n dinamiese teenwoordigheid, die teenwoordigheid van sy openbaring. ${ }^{7}$ )

Eers wanneer die naïef klinkende wêreldbeeld vanwaaruit die epifaniebeskrywing sy materiaal kry, reg begryp word, kom die teologiese belangrikheid van hierdie konsepsie na vore. Die koms van Jahwe word begelei deur verskynsels wat verband hou met die beeld van die hemelse woning van Jahwe. Dit is naamlik die natuurelemente wat hulle tuiste in die hemel het wat die koms van Jahwe begelej. Hierdie elemente is tegelyk die wat sigbaar uit dic hemel kom: bliksemstrale, wolke, wind, stortreën, hael, gepaard met donderslae, gedruis en beroering. In hierdie opsig neem Jahwe die trekke aan van die weergod, 'n godstipe wat in die Oud-Oosterse omgewing bekend is. Die ooreenkomste, ook wat betref besonderhede, is so oorweldigend dat ons nie anders kan as om te bevind dat ons hier met die produkte van 'n kultuurwêreld wyer as Israel te doen het nie. Ook wat betref die verskynsels wat deur die koms van Jahwe tevoorskyn geroep word, is daar sterk ooreenkomste met die omgewing van Israel. Die reaksie van die kosmos op die verskyning van Jahwe is aardskuddings, opdroog van die groot waters en verskroeiing van die plantegroei. Dergelike verskynsels is ook in die Akkadiese tekste aan te wys. ${ }^{8}$ )

Wat dus gebeur as Jahwe te voorskyn tree om in die geskiedenis in te tree, is dat die elemente wat $\mathrm{Hy}$ in die hemel bewaar, saamkom. Hemel en aarde ontmoet mekaar wanneer God verskyn. In hierdie verband is die terme „die hemel afbuig" (nț šmjm Ps. $1^{10}$ ) en „die hemel skeur” (Jes. $63^{19}$ ) besonder beskrywend..$^{9}$ ) Waar Jahwe verskyn, is Hy teenwoordig as die Hemelkoning met sy woning en sy hofstaat. Vandaar dat Sinaĩ en Sion die aanskyn van die hemel aanneem in sommige beskrywings (Ex. $24^{10}$ Jes. 6 ens.) en dat die tempel in sy inrigting iets van die voorstelling van lie hemelse woning van Jahwe weerspieël. Wat opvallend is in die epifanieë waaroor ons nou handel, is dat die toneel van die Godsverskyning die geskiedenis en die kosmos in sy geheel is. Hier word alle perke van die goddelike verskyning en handeling dus deurbreek. Hy gryp in soos Hy in sy toorn en genade besluit. Van sy koms neem die ganse skepping kennis. 
Die aarde beef, berge skud, die fondamente van die hemel sidder, die see en die rivere droog op, die plantegroei verwelk.

Ook in hierdie verband is daar verwantskap met die Oud. Oosterse kultuurvorme aan te wys. Wanneer ons bv. in Neh. $1^{*}$ lees „Hy areig die see en maak dit droog en laat al die riviere opdroog" of in Hab. $3^{9}$,Is dit teen riviere, o Here, teen die riviere dat $u$ toorn ontvlam het? Of geld $u$ grimmigheid die see dat $U$ ry met u perce, u oorwinningswaens?", dan vind ons daar terminologiese herinneringe aan die mitologiese geveg teen die oerwaters, 'n motief wat meermale in die Akkadiese en Ugaritiese tekste voorkom, en wat bv. in Ps. 74 aangewend word om die Skelfseewonder te beskryf. Op grond daarvan meen Westermann dat dié teofanicë laasten: teruggaan op dic oerervaring van Israel van die reddende ingryping van God, naamlik die Skelfseewonder. Jeremias het in die teofaniebeskrywings ook sekere trekke van die tradisie van die dag van die Here herken, naamlik die verdonkering van sterre, die verwoesting van die land en die vernietiging van mense.

Wat die Sinaiteofanie betref, die word meesal aangewys as die bron van alle teofaniebeskrywings deur diegene wat in die teofanieë kultiese geaktualiseerde handelinge sien wat die Sinaîgebeure steeds weer in die hede moet stel. So verklaar Weiser bv. dat dit algemeen aanvaar word en vir die teofaniepsalms ook nie betwyfel kan word nie dat die teofaniebeskrywing oorleweringshistories gesien op die Sinaĩteofanie as oerbeeld teruggaan. Volgens hom is die teofanietradisie tuis in die verbondsfees van die sakrale stammefederasie, en het Ex. 19 en 33v. die feesperikoop gevorm by die Jahweteofanie in die feeskultus. Die teofaniebeskrywings in die Psalms steun dus op die dramatiese afbeelding van die gebeure in die kultus (rookwolke, basuingeskal, feesjubel). ${ }^{10}$ ) Die kritiek op Weiser en sy geesgenote in hierdie opsig het voldoende aangetoon dat die opvattinge nie houdbaar is as verklaring van die herkoms van die epifaniebeskrywing nie, miskien wel in 'n mate van die teofaniebeskrywing. Dit het reeds geblyk dat die tweede komponent van die epifaniebeskrywing, die aanduiding van die begeleidende verskynsels, van oorsprong tuis is in die wêreldbeeld van die ONO, meer spesifek in die beeld van die hemelse woning van die godheid. Spesifiek Israelities is egter die eerste komponent - die vermelding dat God op die aarde kom en handelend op die historiese toneel ingryp. Jeremias het hier te:eg gewys op die Sinaïtradisie wat getuig van die eerse koms van Jahwe, en die mening uitspreek dat hier die oorsprong van hierdie komponent van die epifanie lê.

Wat die literêre tuiste van die epifaniebeskrywing betref, het Westermann reeds ten opsigte van die Psalms aangetoon dat die 
epifanieë tuis is in die samehang van die mededelende lofprysing. "Daarin word 'n God geloof wat in die beslissende uur bygekom het om sy volk te help en hom van sy vyande te red." Jeremias het die gedagte verder gepresiseer deur aan te toon dat die epifaniebeskrywing se oorspronklike tuiste in die oorwinningslied te soeke is, en dat die Deboralied die oorspronklike „sits im Leben" van die epifaniebeskrywing as stylvorm bewaar het. Vanuit hierdie oorspronklike tuiste het die stylvorm dan sy weg gevind na ander literêre tuistes, naamlik himnes, profetiese oordeelsaankondigings, heilsaankondigings en prosaberigte. Dit is egter nie aan te beveel om saam met Jeremias die streng ondersikeid tussen die twee kategorieë van teofaniebeskrywings uit te wis nie.

Die epifaniebeskrywing of bepaalde aanspelings daarop, kom in ' $n$ wye verskeidenheid samehange voor tot in die Nuwe Testament.

Ons tref dit aan in verband met historiese gebeurtenisse en aangekondigde gebeure wat in die toekoms lê. Dit vorm in Deut. 33 die omraming van die stammespreuke, en gee daar die koms en optrede van Jahwe aan as die grond vir die bewoning van die land deur die stamme. In Rigt. 5 vorm dit die kern van die terugblik op die oorwinning van die stamme onder Barak oor die Kanaäniete. In Nah. 1 word die val van Ninivé toegeskryf aan die direkte ingryping van Jahwe in 'n epifanie. In Ps. 18 dank die enkeling sy verlossing aan die direkte ingryping van Jahwe. In Jesaja verskyn die epifaniebeskrywing in die konteks van die oordeelspreuke oor vreemde nasies en die aankondiging van die aanstaande verlossing van die volk uit die ballingskap. In Jes. $63^{19}-64^{3}$ het ons 'n bede om 'n epifanie, en in Jes. 66 vorm die epifanie die kern van die groot eindgerig. Wáár dit egter ook al verskyn, het die epifaniebeskrywing of die aanspeling daarop steeds die funksie dat dit die aandag vestig op die beslissende koms en ingryping van God. Dit is sekerlik nie toevallig nie dat ons in die weergawe van die gebeure rondom die kruisiging van Christus en die uitstorting van die Heilige Gees elemente uit die epifaniebeskrywing aantref nie.

Vriezen het gewys op die teologiese belangrikheid van die aanwending van die epifanieë by digterlike weergawes van historiese gebeurtenisse: „Dit toon aan dat die optrede van God in die geskiedenis as 'n uittrede van Hom uit die Ontoeganklike waar Hy woon, beskou word." Ons verkeer dus met die epifanie op die terrein van Gods openbaring in die geskiedenis. Die epifanie betuig die reële teenwoordgheid van God op die wêreldtoneel, ' $n$ teenwcordigheid wat nie staties vasgevang is in ' $n$ kultiese verblyf nie. Dit is 'n dinamiese openbaring waarin sy 
soewereine vryheid nie verminder word nie. Sy koms geskied ten behoewe van sy verhouding tot sy uitverkorenes. Die verskynsels wat sy koms vergesel en die verskynsels wat deur sy koms na vore geroep word, het die funksie dat dit die kosmiese betrokkenheid by sy optrede weerspieël. Die magtigste beroeringe in die natuur word in die epifaniebeskrywing betrek om daarmee die alles oortreffende krag van sy werk in die geskiedenis aan te dui. Die himne waarmee die boek Nahum begin, is hiervan 'n goeie illustrasie. Dit gaan in Nahum om die val van Ninivé. Vir die historikus sou die val van hierdie magtige stad sy grond hê in politieke en ekonomiese faktore en sou die magsoorwig van die verenigde Babiloniese en Mediese leërs die oorwinning verklaar. Vir die digterprofeet staan die saak anders. Wat met Ninivé gebeur, is die werk van God self. Hy herken in daardie stryd die verskynsels wat eie is aan die koms van God en sy ingryping. Die strydwaens van die invallers het die voorkoms van fakkels en bliksemstrale, die swaarde en spiese lyk soos vlamme en bliksemstrale, die paleis wat verkrummel onder die aanslae van die stormramme ,smelt weg" soos die heuwels voor die tred van die Here, die vuur wat die grendels van die stad verteer en sy strydwaens in rook laat opgaan, is die vuur wat die koms van die Here vergesel.

Hier het ons 'n naasmekaar van epifaniebeskrywings en historiese gegewenheid. Ook in die geval van Deut. 33, Rigt. 5 het ons so 'n naasmekaar. Hieruit blyk dat die reële teenwoordigheid van die Here nie geskei kan word van die middellike realisering daarvan in die oorlog nie. Die epifaniebeskrywing is geloofsuitspraak wat die aards-historiese omvorm tot bowetydelik-kosmiese. In elke teofaniebeskrywing is dit duidelik dat die open baring van God as die handelende Kryger steeds met behoud van sy ontoeganklikheid geskied. Hoe antropomorf die werkwoorde wat sy koms beskryf ookal is, sy gestalte bly onsienlik. Die verskyning van die Hemelkoning is net kenbaar aan sy retinue. Openbaring in die geskiedenis in die taal van die epifanie is nie ingryping in die tyd alleen nie maar ook in die ruimte. Hemel en aarde ontmoet mekaar in die epifanie. Geografie en teologie word vennote in die lof van God.

As teologiese konsekwensies van die epifanie kan ons tenslotte saam met Jeremias ook nog noem die betuiging van die onweerstaanbare mag van Jahwe, wat veral uitgedruk word in die beroeringe van die natuurlike wêreld, en daarnaas die lewendigheid, dinamiek en bewoënheid van sy gestalte. Daarmee is miskien enkele trekke van die kerugmatiese inhoud van so 'n mitologies-klinkende, onwerklikvoorkomende stuk openbaringsgetuienis soos die epifanie aangedui. ") 


\section{Aantekeninge}

1. Vir 'n oorsig van die geskiedenis van die begrip vgl. die art. Teophany, deur E. Kautsch, in Encyclopaedia of Religious Knowledge (Schaff-Herzog)

2. Die vormkritiese analise is afkomstig van C. Westermann, Das Loben Gottes in den Psalmen', 1963, p. 73

3. Vgl. Th. C. Vriezen, Hoofdlijnen der Theologie van het Oude Testament $^{3}$, 1966, p. 206; en H.-P. Müller, Vetus Testamentum xiv, p. 190

4. Vgl. G. R. Jriver, Canaanite Myths and Legends, 1956, p. $81,128,141$; Vriezen, a.w., p. 368

5. Ern. Frid. Car. Rosenmüller, Scholia in Vetus Testamentum, 1824, Volumen Tertium, p. 650

6. Martin Noth, Geschichte Israels .

7. Walther Eichrodt, Theologie des Alten Testaments, ${ }^{4}$ Teil $2 / 3,1961$, p. 127

8. Vgl. Jörg Jeremias, Theophanie, 1965, p. $72 \mathrm{vv}$

9. Norman C. Habel, He who stretches out the Heavens, in The Catholic Biblical Quarterly xxxiv: 4 Oct. 1972, p. 417-430, verklaar verkeerdelik Ps. $18^{10}$ saam met ander tekste om aan te tcon dat dit gaan om die „opslaan" van die hemele as 'n kosmiese tent. Die gebruils van die ww. jrd in Ps. $18^{10}$ bepaal ook die betekenis van nth.

10. Artur Weiser, Zur Frage nach den Baziehungen der Psalmen zum Kult: Die Darstellung der Theophanie in den Psalmen und im Festkult, in Glaube und Geschichte im Alten Testament, 1961, p. 303-321; Vgl. verder Sigmund Mowinckel, The Psalms in Israel Worship, 1967, p. 113 en elders, wat die epifanie in die troonbestygingsfees van Jahwe tuisbring. en H.-P. Müller, Die kuitische Darstellung der Theophanie, Vetus Testamentum xiv, 1964 , p. 183-191, wat die rituele daarstelling van die Sinaïteofanie in die Amfiktyonekultus ooreenkomstig die gebeure in Rigt. $7^{16}{ }_{-22} .1$ Sam. $4_{-}^{48}$ en Jos. 6 wil voorstel.

11. Vgl. verder Gwyneth Dindsor, Theophany in Theology, Vol LXXV, 1972, p .411-416 